GU J Sci, Part C, 6(3): 644-658 (2018)

Gazi Üniversitesi
Fen Bilimleri Dergisi
PART C: TASARIM VE TEKNOLOJI
dergipark.gov.tr/http-gujsc-gazi-edu-tr

\title{
Sanal Hücresel Üretim Sistemi İçin Üretim Kontrol Sisteminin Belirlenmesi
}

\author{
Ömer Faruk YILMAZ \\ Karadeniz Teknik Üniversitesi, Mühendislik Fakültesi, Endüstri Mühendisliği Bölümü, 61080, Ortahisar/TRABZON
}

\begin{abstract}
$\underline{\text { Öz }}$
Makale Bilgisi

Başvuru: 22/2/2018

Düzeltme: 18/05/2018

Kabul: 29/05/2018

Sanal hücresel üretim sistemi (SHÜS) yeni ürün kabulüne izin vermekle birlikte talepteki değişkenliğe karşılık verebilmektedir. Böylece, üretim ortamında herhangi bir değişikliğe gerek duyulmadan üretim gerçekleştiren firmalara avantajlar sunmaktadır. SHÜS için uygun üretim kontrol sisteminin belirlenmesi oldukça önemli bir konudur ve bu çalışma içerisinde bu probleme odaklanılmıştır. SHÜS için en uygun alternatifin seçilmesi için dört farklı alternatif aralık değerli sezgisel bulanık analitik hiyerarşi prosesi (ADSBAHP) metoduyla beş farklı kriter 1şığında değerlendirilmiştir. Sonuçlar SHÜS için CONWIP üretim kontrol sistemi alternatifinin diğer alternatiflere üstünlük sağladığını göstermektedir.
\end{abstract}

Anahtar Kelimeler

Üretim kontrol sistemleri Aralk değerli sezgisel bulanık analitik hiyerarşi prosesi

Sanal hücresel üretim

sistemi

\section{Keywords}

Production control

systems

Interval-valued

intuitionistic fuzzy

analytic hierarchy

process

Virtual cellular

manufacturing system

\section{Determination of Production Control System for Virtual Cellular Manufacturing System}

\begin{abstract}
Virtual cellular manufacturing system (VCMS) allows production system to accept a new type of product and copes with fluctuations in demand. Therefore, it offers opportunities for manufacturing firms by designing the cells without changing the layout of production environment. Determination of proper production control system for VCMS is an important topic and this study focuses on this problem. In order to select the best production control system for the VCMS, four alternatives are evaluated under five criteria by applying interval-valued intuitionistic fuzzy analytic hierarchy process (IVIFAHP) method. The results show that CONWIP production control system alternative superior to others alternatives for VCMS with respect to criteria.
\end{abstract}

\section{GİRIŞ (INTRODUCTION)}

Günümüzde ürün yaşam çevrimlerinin kısalması, ürün çeşitliğinin ve ürün taleplerinin değişkenliğinin artması farklı çeşitte hücresel üretim sistemlerinin ortaya çıkmasına neden olmuştur. Temel anlamda, hücresel üretim sistemleri (HÜS) grup teknolojisi prensiplerinin bir üretim ortamına uyarlanması olarak tanımlanabilir [1]. Benzer ürünlerin ve gerekli makinelerin fiziksel olarak bir araya gelmesi sonucu ürün-makine aileleri oluşturulmakta ve her ürün ailesi farklı bir hücreye tahsis edilmektedir [2]. Hücresel üretimin kullanılması ile birlikte üretim temin süresi düşürülmekte, çıktı oranı yükselmekte, üretkenlik artmakta ve süreç içi stok azalmaktadır [3,4]. Hücresel üretimin avantajlarının yanı sıra dezavantajları da bulunmaktadır. $\mathrm{Bu}$ dezavantajlar özellikle rotalama esnekliği, talep değişkenliği, kapasite kullanımı ve standart olmayan ürünlerin olduğu durumlarda ortaya çıkmaktadır [5]. 
Geleneksel bir HÜS' de makineler için bir yerleşim düzeni belirlenmekte ve düzen değiştirilmemektedir. Ancak ürün taleplerinin düzensiz olması ve ürün çeşitliliğinin değişkenlik göstermesi nedeniyle HÜS yapısının değişkenliklere kolay adapte edilmesi gerekmektedir. Sanal hücresel üretim sistemleri (SHÜS) bu adaptasyonu sağlayabilmektedir. Ürün-makine ailelerinin oluşumuna izin verilen SHÜS ‘ de makinelerin yerleşimleri değişmemekle birlikte sanal hücreler oluşturulmaktadır [6]. SHÜS' de hücreler ürün ailesine tahsis edilmekte ve zaman içerisinde bu tahsis değişmektedir. Talep ve ürün çeşitliliğinde değişiklik yaşandığında bir sanal hücrede bulunan makineler tekrar farklı bir ürün ailesi için tahsis edilebilmektedir [7]. Makine yerleşimlerinin değişmemesi maliyet açısından önemli olduğu kadar makine kullanım oranlarını da arttırmaktadır [8]. Ancak ürün ailelerinin partiler halinde makineleri dolaşıyor olması SHÜS için çizelgeleme problemlerini oldukça zor bir hale getirmektedir [9].

Yukarıda da bahsedildiği üzere ürün çeşitliliğinin yüksek olduğu ve talebin değişken olduğu durumlarda üretim sistemi olarak SHÜS kullanılabilmektedir. $\mathrm{Bu}$ sistemin artan ürün çeşitliliğine yanıt verebilmesi için üretimin etkin bir şekilde kontrol edilmesi ve planlanması gerekmektedir [5]. Üretim sistemlerinin kontrol ve planlanmasında üretim kontrol sistemleri kullanılmaktadır. $\mathrm{Bu}$ nedenle etkin bir uygulama için doğru sistemin belirlenmesi oldukça önemli bir konudur.

Üretim kontrol sistemleri temel olarak itme ve çekme olmak üzere ikiye ayrılmaktadır. Her iki sistem türü için literatürde fazla sayıda çalışma bulunmaktadır ve bu çalışmalarda detaylı tanımlamaları yapılmıştır. Bir üretim sisteminde üretim hammadde bulunduğu sürece devam ediyorsa o üretim sistemi itme esaslı kontrol edilmektedir. Aksine, bir üretim sistemindeki çıktılar sistemin bitiş noktasından gelen bildirimlere göre belirleniyorsa bu durumda o üretim sisteminin çekme esaslı yönetildiği anlaşılmaktadır [10].

Her iki kontrol sisteminin melez olarak kullanıldığ 1 üretim kontrol yöntemi de bulunmaktadır. $\mathrm{Bu}$ çalışmada değerlendirilmesi yapılacak olan alternatifler itme, çekme ve melez kontrol sistemlerini kapsayacak şekilde belirlenmiştir. Bu amaçla SHÜS için uygun olabilecek dört farklı alternatif belirlenmiştir. Bu alternatifler şunlardır; Kanban üretim kontrol sistemi, CONWIP üretim kontrol sistemi, ürün salınım (ÜS) üretim kontrol sistemi ve itme esaslı (IE) üretim kontrol sistemidir. Bu alternatiflerden Kanban üretim kontrol sistemi çekme esaslı çalışırken, CONWIP ve ÜS melez üretim kontrol sınıfına girmekte ve İE itme esaslı çalışmaktadır.

Kanban, Toyota üretim sisteminde kullanılmak üzere Taichi Ohno tarafından tanıtılmıştır ve 1953 y1lından itibaren kullanılmaktadır. Kanban çekme esaslı üretim kontrol sistemleri arasında en çok kullanılan yöntemlerden bir tanesidir. Bunun nedeni, kullanımının kolaylığı ve gelişmeleri teşvik etmesidir. Kanban iki ardıl operasyonu birleştirme mantığı üzerinden çalışmaktadır. Ardıl operasyon ihtiyacını öncül operasyondan kart veya sinyal gönderim yoluyla temin etmektedir. Kanban merkezi olmayan karar verme yapısını kullanmaktadır [11].

Spearman ve diğ. [12] Kanban üretim kontrol sisteminin alternatif çekme esaslı bir yöntem olan CONWIP sistemini tanıtmışlardır. Bu üretim kontrol sistemi üretim hattının sonundan üretim hattının başına sinyal gönderilmesi ile çalışmaktadır. Bu sayede üretim akışı içerisindeki süreç içi stok miktarını kontrol altında tutmaktadır. CONWIP, çekme ve itme sistemlerinin avantajlarını aynı anda kullanmaktadır. Üretime başlamak için çekme kontrolü uygulanırken üretim içindeki akış itme kontrolü ile sağlanmaktadır [5].

ÜS üretim kontrol sistemi hangi ürünün ne zaman ve hangi şartlar altında üretim sistemine salınacağının belirlenmesini sağlamaktadır [13]. Bu kararların verilmesi ile birlikte üretim sistemi içerisinde işyükü kontrolü sağlanabilmektedir. Ürünlerin üretim sistemine salınması sonrasında üretimlerine başlanabilmektedir. Ürünlerin hangi sırayla üretilecekleri iş yükünü etkileyen bir diğer unsurdur. $\mathrm{Bu}$ nedenle genellikle ÜS ile çizelgeleme problemleri birleştirilmektedir. $\mathrm{Bu}$ sayede üretim sistemine salınan ürünlerin çizelgelenmesi de gerçekleştirilmektedir. 
İE ile tüm ürünler üretilmek amacıyla üretim sistemine itilmektedir. Üretim akışı içerisindeki süreç içi stok miktar kontrol edilememektedir. Ayrıca işyükü kontrolü uygulanamamaktadır [14].

$\mathrm{Bu}$ çalışma içerisinde SHÜS için uygun olan üretim kontrol sisteminin belirlenmesi amaçlanmaktadır. Bu nedenle son yıllarda kullanımı artmış olan aralık değerli sezgisel bulanık analitik hiyerarşi prosesi (ADSBAHP) metodu alternatifler arasından en uygun olanını belirlemek için uygulanmıştır.

Çalışmanın ikinci aşamasında üretim kontrol sistemleri ve aralık değerli sezgisel bulanık kümeler başlıkları altında literatürde daha önce yapılan çalışmalara yer verilmiştir. Çalışmanın üçüncü aşamasında belirlenen alternatif ve kriterler sunulmuş ve açıklamaları gerçekleştirilmiştir. Çalışmanın dördüncü aşamasında önerilen ADSBAHP yöntemi adım adım detaylı olarak açıklanmıştır. Beşinci aşamada önerilen ADSBAHP yönteminin SHÜS için uygun üretim kontrol sisteminin belirlenmesi amaciyla uygulanmasına yer verilmiştir. Çalışmanın son ve altıncı aşamasında elde edilen sonuç ve bulgulara yer verilmiştir.

\section{LITERATÜR TARAMASI (LITERATURE REVIEW)}

Literatürde üretim kontrol sistemleri ile ilgili yayınlanmış birçok çalışma bulunmaktadır. $\mathrm{Bu}$ çalışmaların bir kısmında uygun sistemin belirlenmesi için varsayımlar kullanılmıştır. En uygun kontrol sisteminin belirlenmesi için benzetim tabanlı modellerin oluşturulduğu çalışmalar da bulunmaktadır. Ancak çok kriterli karar verme yöntemleri ile gerçekleştirilmiş çalışma sayısı oldukça azdır. Yazarların araştırmaları sonucunda bulanık sezgisel AHP yöntemi kullanılarak üretim kontrol sisteminin seçimi ile ilgili çalışma olmadığı görülmüştür. Bu anlamda mevcut çalışma literatürdeki bu boşluğu doldurmaktadır. Bu çalışmanın bir diğer önemli katkısı ise literatürde daha önce SHÜS için gerçekleştirilmiş ve üretim kontrol politikalarını ele alan bir çalışma olmaması nedeniyle bu noktaya odaklanılmış olmasıdır.

Bu kısım iki alt başlığa ayrılmış ve bu başlıklar altında üretim kontrol politikaları ve bulanık sezgisel AHP ile ilgili gerçekleştirilmiş çalışmalara yer verilmiştir.

\section{1 Üretim Kontrol Sistemleri (Production Control Systems)}

Literatürde üretim kontrol sistemleri ile ilgili çalışmalar üç sınıfa ayrılmaktadır. Bu sınıflardan ilkini matematiksel model kullanan çalışmalar oluşturmaktadır, ikincisini tasarım çalışmaları oluştururken üçüncüsünü çekme/itme sistemlerini ele alan çalışmalar oluşturmaktadır.

Steele ve Malhotra [15] çalışmalarında malzeme ihtiyaç planlaması, Kanban ve periyodik parti kontrolünü bir hücresel üretim sistemi için karşılaştırarak üretim ortamının sistem seçiminde oldukça önemli olduğunu vurgulamışlardır. Li ve Barnes [16] sipariş tipi atölye üretim merkezine hücresel üretimin Kanban ile adaptasyonun hazırlık süresinin düşürülmesine bağlı olduğunu belirtmişlerdir. Ryan ve Choobineh [17] tarafindan geliştirlen planlama prosedürü her tip ürün için sabit süreç içi stok seviyelerini CONWIP kontrolü ile sağlamışlardır. Islam ve Mohamed [18] itme tipi üretim sistemi ile tam zamanında üretimin birlikte olma durumunu incelemişlerdir. Sharma ve Agrawal [19] yüksek talep değişkenliğine sahip bir üretim ortamında en uygun üretim kontrol politikasının seçimi için AHP algoritmasını önermişlerdir. Kanban, CONWIP ve melez üretim kontrol politikalarının alternatif olarak belirlendiği çalışmada Kanban ve CONWIP politikalarının farklı senaryolar altında birbirlerine üstünlük kurduklarını belirtmişlerdir. Li [20] CONWIP kontrol sisteminin kalite iyileştirmeleri, hazırlık süresi düşürme ve yerleşim değişimlerinde Kanban sistemine üstünlük sağladığını belirtmiştir. Moreira ve Alves [21] benzetim çalışmasıyla ÜS kontrol sisteminin sipariş tipi atölye performansını arttırdığını belirmişlerdir. Gong ve diğ. [22] çalışmalarında aynı üretim ortamında CONWIP, Kanban ve malzeme ihtiyaç planlaması sistemlerinin çok kriterli olarak karşılaştırılmasında ürün pozisyon bilgilerini kullanmışlardır. Müller ve diğ. [23] itme-Kanban üretim kontrol konseptini tanıtarak etkinliğini benzetim tekniğiyle analiz etmişlerdir. Romagnoli [24] CONWIP sisteminin sipariş üzerine üretim gerçekleştiren bir üretim ortamına uyarlanması 
üzerine çalışmıştır. Yazar CONWIP sisteminin karmaşık sistemler için verimliliğini vurgulamıştır. Thürer ve diğ. [25] sipariş tipi atölye üretim ortamının performansını arttırmak için ÜS sisteminin kullanımından faydalanmışlardır. Konefal [26] çevrim süresi ve zamanında tamamlanma oranlarının yüksek değişim gösterdiği üretim ortamında Kanban ve CONWIP sistemlerini karşılaştırarak CONWIP sisteminin performans üzerindeki iyileştirmelerini vurgulamıştır.

Literatürün büyük bir kısmı incelendiğinde daha önce CONWIP, Kanban, ÜS ve İE sistemlerini SHÜS için ele alan bir çalışma olmadığı gözlemlenmiştir. Bu durum bu çalışmanın orijinalliğini vurgulamaktadır.

\subsection{Aralık Değerli Sezgisel Bulanık Kümeler (Interval-valued Intuitionistic Fuzzy Sets)}

Bu çalışma içerisinde tipik çok kriterli seçim problemi olan SHÜS için uygun üretim kontrol sisteminin belirlenmesine odaklanılmıştır. Seçilen yöntem aralık değerli sezgisel bulanık kümeleri (ADSBK) kullandığı için bu kısımda literatürdeki çalışmalara yer verilmiştir.

Atanassov [27] hem sezgisel bulanık kümeleri hem de aralık değerli bulanık kümeleri kapsayan aralık değerli sezgisel bulanık kümeleri tanıtmışlardır. Yazarlar ADBSK için belirsizlik ile başa çıkmakta diğer tip sezgisel bulanık kümelerden daha iyi performans sergilediğini belirtmişlerdir. Xu ve Chen [28] öncelik bilgilerinin birleştirilmesi için sıralı ağırlıklı birleştirme operatörü ile melez birleştirme operatörünü kullanılmışlardır. Aralık değerli sezgisel değerlendirme matrisi ile grup karar verme için bir yaklaşım önermişlerdir. Xu [29] aralık değerli sezgisel bulanık matrisi tanıtarak çok kriterli karar verme için bir metot önermiştir. Chen ve diğ. [30] çok kriterli karar verme problemleri için ADSBK kullanan bir yöntem önermişlerdir. Yöntemde doğrusal programlama sayesinde aralık değerli yerine kesin değerler kullanılmıştır. Chen ve diğ. [31] alternatifleri göz önünde bulundurarak uzmanların görüşlerini bulanık değerler üzerinden yansıtan ve çok kriterli karar vermede kullanılan ADSBK ile bir metot önermişlerdir. Zhang ve diğ. [32] geliştirdikleri optimizasyon modeli ile ADSBK kullanan çok kriterli karar verme problemleri için ölçüt ağırlıklarının belirlenmesini sağlamışlardır. Jin ve diğ. [33] geliştirdikleri programlama modeliyle kriterlerin ağırlıklarının optimal olarak belirlenmesini sağlayarak ADSBK kullanılan çok kriterli karar vermede uygulamışlardır. Tong ve Yu [34] yeni bir çok ölçütlü karar verme metodu geliştirerek bilinmeyen ölçüt ağırlıklarını ADSBK çerçevesinde belirlemişlerdir. Onar ve diğ. [35] En uygun rüzgar enerjisi alternatifinin belirlenmesi için ADSBK ile AHP yöntemini birleştirerek ADSBAHP adıyla kullanmışlardır. Kahraman ve diğ. [36] ADSBK kullanarak geliştirdikleri bulanık kar/maliyet metodunu rüzgar enerjisi teknoloji yatırımlarının değerlendirilmesinde kullanmışladır. Kahraman ve diğ. [37] ortalama çözüm değerinden uzaklığı esas alarak ABSBK üzerine geliştirdikleri metodu katı atık dönüşümü için yer seçim probleminde kullanmışlardır.

Literatürde aralık değerli bulanık kümeleri esas alarak hazırlanan çok kriterli karar verme çalışmalarına incelendiğinde SHÜS için uygun kontrol sisteminin seçimine odaklanılan bir çalışma olmadığı gözlemlenmiş̧tir. Bu nedenle bu çalışma literatürdeki boşluğu dolduracaktır.

\section{ALTERNATIFLER VE KRITTERLER (ALTERNATIVES AND CRITERIA)}

$\mathrm{Bu}$ kısımda üretim kontrol sistemlerinin değerlendirilmesi için literatürdeki çalışmalardan ve karar takımından (KT) yararlanılarak ortak kriterler belirlenmiştir. Karar takımı akademisyenler ve gerçek üretim ortamında çalışan uzmanlardan oluşmaktadır. Kriterlerin belirlenmesi aşamasında [15], [16], [18], [19], [21], [23], [24] ve [38] çalışmalarından yararlanılmıştır. 


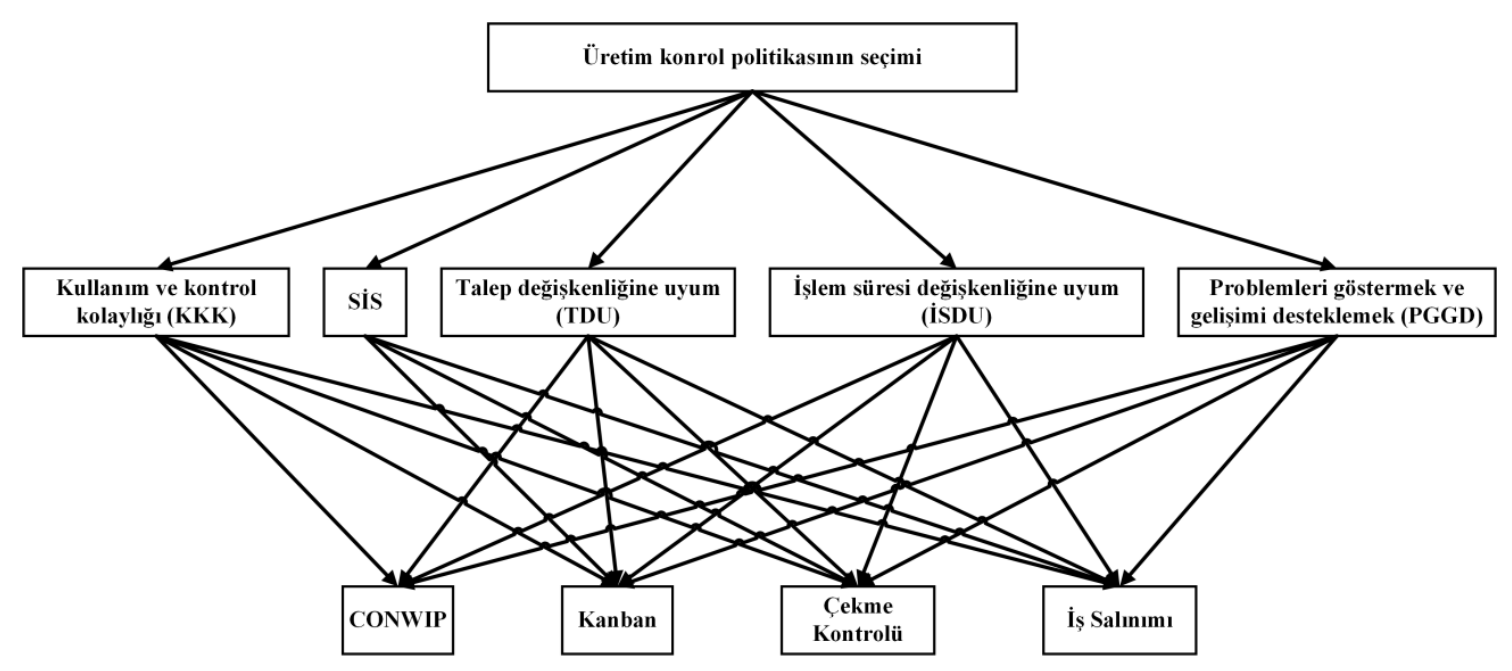

Şekil 1. Seçim probleminin hiyerarşik yapısı

Üretim kontrol sistemi olarak dört alternatif belirlenmiştir. Bu alternatifler arasından seçim yapılabilmesi için beş kriter belirlenmiştir.

"Kullanım ve kontrol kolaylığı" kriteri üretim kontrol sistemlerinin kullanıcılar tarafından rahatlıkla uygulanabilirliği ve kontrol edilebilirliği ile ilgilidir.

"Süreç içi stok (SİS)" kriteri üretim kontrol sistemlerinin üretim akışı içerisindeki süreç içi stok miktarını ne derece etkilediği ile ilgilidir.

“Talep değişkenliğine uyum” kriteri üretim kontrol sistemlerinin talep değişkenliğine ne derece uyum sağladığ 1 ile ilgilidir.

"İ̧̧lem süresi değişkenliğine uyum" kriteri üretim kontrol sistemlerinin işlem süresi değişkenliğine ne derece uyum sağladığı ile ilgilidir.

"Problemleri göstermek ve gelişimi desteklemek" kriteri üretim kontrol sistemlerinin problemleri gösterebilmesi ve sürekli iyileştirmeyi teşvik etmesi ile ilgilidir.

\section{4. ÖNERILEN ADSBAHP YÖNTEMİ (PROPOSED IVIFAHP METHOD)}

Önerilen çok kriterli karar verme yöntemi Onar ve diğ. [35] çalışmasında kullanmış oldukları ADSBAHP yönteminden uyarlanmıştır ve bu kısımda adımlarına detaylı olarak yer verilmektedir.

Adım 1. Tablo 1 kullanarak her uzmandan sözel ikili karşılaştırma matrislerinin elde edilmesi.

Tablo 1. Sözel ikili karşılaştırma matrisi

\begin{tabular}{ccccc}
\hline Uzman i & C1 & C2 & $\ldots$ & Cn \\
\hline $\mathbf{C 1}$ & EE & & & \\
C2 & & EE & & \\
$\ldots$ & & & EE & \\
$\mathbf{C n}$ & & & & EE \\
\hline
\end{tabular}

Adım 2.Tablo 1 içerisindeki sözel verileri tablo 2' de karşılık gelen sayısal değerlerine çevir. 
Tablo 2. Sözel ölçekler ve karşıllı gelen ADSBK

\begin{tabular}{lc}
\hline Sözel ifadeler & Üyelik ve üyelik olmayan \\
\hline Kesin düşük (KD) & $([0,0.2],[0.5,0.8])$ \\
Çok düşük (ÇD) & $([0.1,0.3],[0.4,0.7])$ \\
Düşük (D) & $([0.2,0.4],[0.3,0.6])$ \\
Orta düşük (OD) & $([0.3,0.5],[0.2,0.5])$ \\
Eşit (E) & $([0.4,0.6],[0.2,0.4])$ \\
Orta yüksek (OY) & $([0.5,0.7],[0.1,0.3])$ \\
Yüksek (Y) & $([0.6,0.8],[0,0.2])$ \\
Çok yüksek (ÇY) & $([0.7,0.9],[0,0.1])$ \\
Kesin yüksek (KY) & $([0.8,1.0],[0,0])$ \\
\hline
\end{tabular}

Adım 3. Denklem 4.1 kullanarak aralık değerli sezgisel bulanık ikili karşılaştırma matrislerini birleştir. (Aralık değerli sezgisel bulanık ortalama)

$$
A D S B O=\left(\left[1-\left(\prod_{i=1}^{n}\left(1-a_{i}\right)\right)^{1 / n}, 1-\left(\prod_{i=1}^{n}\left(1-b_{i}\right)\right)^{1 / n}\right], \times\left[\left(\prod_{i=}^{n} c_{i}\right)^{1 / n},\left(\prod_{i=1}^{n} d_{i}\right)^{1 / n}\right]\right)
$$

Adım 4. Skor değerlendirme matrisini $\tilde{S}=\left(s_{i, j}\right)_{n^{*} n}=\left\lfloor\mu_{g_{i, j}}^{-}-v_{g_{i, j}}^{+}, \mu_{g_{i, j}}^{+}-v_{g_{i, j}}^{-}\right\rfloor$ve aralık çarpım matrisini $\tilde{A}=\left(\tilde{a}_{i, j}\right)_{n^{*} n}=\left[10^{\left(\mu_{s i, j}^{-}-v_{g i, j}^{+}\right)}, 10^{\left(\mu_{s i, j}^{+}-v_{s i, j}^{-}\right)}\right]$hesapla.

$$
\begin{aligned}
& \left.\left.\tilde{S}=\left[\begin{array}{l}
\left\lfloor\mu_{g_{1,1}}^{-}-v_{g_{1,1}}^{+}, \mu_{g_{1,1}}^{+}-v_{g_{1,1}^{-}}^{-}\right\rfloor \\
{\left[\mu_{g_{n, 1}}^{-}-v_{g_{n, 1}}^{+}, \mu_{g_{n, 1}}^{+}-v_{g_{n, 1}}^{-}\right.}
\end{array}\right] \frac{\left.\mid \mu_{g_{1, n}}^{-}-v_{1, n}^{+}, \mu_{1, n}^{+}-v_{g_{1, n}}^{-}\right\rfloor}{\left[\mu_{g_{n, n}}^{-}-v_{g_{n, n}}^{+}, \mu_{g_{n, n}}^{+}-v_{g_{n, n}}^{-}\right.}\right\rfloor\right]
\end{aligned}
$$

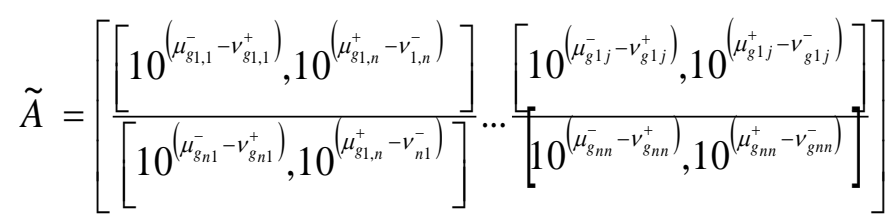

Adım 5. $\tilde{w}_{i}$ aralıklarını hesaplayarak aralık çarpım matrisinin $\tilde{A}$ öncelik vektörünü hesapla

$$
\tilde{w}_{i}=\left[\frac{\sum_{j=1}^{n} \tilde{a}_{i j}^{-}}{\sum_{i=1}^{n} \sum_{j=1}^{n} \tilde{a}_{i j}^{+}}, \frac{\sum_{j=1}^{n} \tilde{a}_{i j}^{+}}{\sum_{i=1}^{n} \sum_{j=1}^{n} \tilde{a}_{i j}^{-}}\right]=\left[w_{i}^{-}, w_{i}^{+}\right]
$$

Adım 6. Denklem 4.3 kullanarak olabilirlik derece matrisi $P$ hesapla. 


$$
P\left(w_{i} \geq w_{j}\right)=\frac{\min \left\{L_{w i}+L_{w j}, \max \left(w_{i}^{+}-w_{j}^{-}, 0\right)\right\}}{L_{w i}+L_{w j}}
$$

Adım 7. Denklem 4.4 kullanarak $P$ matrisini önceliklendir.

$$
w_{i}=\frac{1}{n}\left[\sum_{j=1}^{n} p_{i j}+\frac{n}{2}-1\right]
$$

Adım 8. Denklem 4.5 kullanarak alternatiflerin normalize ağılıklarını hesapla.

$$
w_{i}^{T}=\frac{w_{i}}{\sum_{i=1}^{n} w_{i}}
$$

Adım 9. Her alternatif için Adım (1)-(8) arasını uygula ve alternative j $(\mathrm{j}=1,2, ., \mathrm{m})$ ve kriter i $(\mathrm{i}=1,2, . ., \mathrm{n})$ için skor değerlerini $\varphi_{i j}$ hesapla.

Adım 10. Denklem 4.6 kullanarak her alternatifin öncelik değerlerini hesapla.

$$
P_{j}=\sum_{i=1}^{n} w_{i} \varphi_{i j}
$$

Adım 11. En yüksek öncelik değerine sahip alternatifi seç

\section{5. ÖNERILLEN YÖNTEMIN UYGULANMASI (APPLICATION OF PROPOSED METHOD)}

Bu kısımda önerilen MCDM metodu (ADSBAHP) kullanılarak SHÜS için en uygun üretim kontrol sistem alternatifin seçimi gerçekleştirilmektedir. İlk olarak uzmanlar kriterler için ikili karşılaştırmalar gerçekleştirmiştir. Uzman değerlendirmelerine Tablo 3' de yer verilmektedir. Her kriter için alternatiflerin ikili karşılaştırmalarına Tablo 4' de yer verilmektedir. Birleştirilmiş karşılaştırma matrisine Tablo 5 içerisinde yer verilmektedir. Tablo 6 skor değerlendirme matrisini göstermektedir. Aralık çarpım matrisi Tablo 7' de gösterilmektedir. Tablo 8' de öncelik vektörüne yer verilmektedir. Tablo 9' da olabilirlik derece matrisi ve kriterlerin ağırlıkları gösterilmektedir. Alternatiflerin sıralandırılması Tablo 10' da gösterilmektedir. Hangi üretim kontrol metodunun SHÜS için en uygun sonuç verdiği bu tablo değerlendirilerek bulunmaktadır. En iyi sonucu veren alternatif CONWIP alternatifidir. 
Tablo 3. Uzmanlar tarafından kriterlerin ikli karşılaştırılması

\begin{tabular}{|c|c|c|c|c|c|}
\hline & Kullanım ve kontrol kolaylığ1 & SİS & Talep değişkenliğine uyum & İşlem süresi değiş. uyum & Prob. göster. geliş. destek. \\
\hline \multicolumn{6}{|l|}{ Uzman 1} \\
\hline Kullanım ve kontrol kolaylığı & $\mathrm{EE}$ & ÇD & $\mathrm{KD}$ & $\mathrm{Y}$ & OD \\
\hline SİS & & $\mathrm{EE}$ & $\mathrm{D}$ & ÇY & OY \\
\hline Talep değişkenliğine uyum & & & $\mathrm{EE}$ & KY & $\mathrm{Y}$ \\
\hline İşlem süresi değiş. uyum & & & & $\mathrm{EE}$ & ÇD \\
\hline Prob. göster. geliş. destek. & & & & & $\mathrm{EE}$ \\
\hline \multicolumn{6}{|l|}{ Uzman 2} \\
\hline Kullanım ve kontrol kolaylığ & $\mathrm{EE}$ & ÇD & $\mathrm{D}$ & ÇD & KD \\
\hline SİS & & $\mathrm{EE}$ & $\mathrm{OY}$ & KY & OD \\
\hline Talep değişkenliğine uyum & & & $\mathrm{EE}$ & $\mathrm{Y}$ & ÇD \\
\hline İşlem süresi değiş. uyum & & & & $\mathrm{EE}$ & KD \\
\hline Prob. göster. geliş. destek. & & & & & $\mathrm{EE}$ \\
\hline \multicolumn{6}{|l|}{ Uzman 3} \\
\hline Kullanım ve kontrol kolaylığı & $\mathrm{EE}$ & OD & $\mathrm{Y}$ & ÇY & ÇY \\
\hline SİS & & $\mathrm{EE}$ & $\mathrm{Y}$ & KY & ÇY \\
\hline Talep değişkenliğine uyum & & & $\mathrm{EE}$ & $\mathrm{Y}$ & OY \\
\hline İşlem süresi değiş. uyum & & & & $\mathrm{EE}$ & OD \\
\hline Prob. göster. geliş. destek. & & & & & $\mathrm{EE}$ \\
\hline
\end{tabular}


Tablo 4. Uzmanlar tarafindan kriterlerin ikli karşılaş̧tırılması

\begin{tabular}{|c|c|c|c|c|c|c|c|c|c|c|c|c|}
\hline & Uzman 1 & & & & Uzman 2 & & & & Uzman 3 & & & \\
\hline KKK & CONWIP & Kanban & İE & ÜS & CONWIP & Kanban & $\dot{\mathrm{I}} \mathrm{E}$ & ÜS & CONWIP & Kanban & $\dot{\mathrm{I}} \mathrm{E}$ & ÜS \\
\hline CONWIP & $\mathrm{EE}$ & ÇY & KY & $\mathrm{Y}$ & EE & $\mathrm{Y}$ & ÇY & $\mathrm{Y}$ & $\mathrm{EE}$ & KY & $\mathrm{Y}$ & ÇY \\
\hline Kanban & & $\mathrm{EE}$ & $\mathrm{Y}$ & $\mathrm{EE}$ & & $\mathrm{EE}$ & $\mathrm{Y}$ & Y & & $\mathrm{EE}$ & ÇY & $\mathrm{Y}$ \\
\hline İE & & & EE & $\mathrm{D}$ & & & $\mathrm{EE}$ & CDD & & & EE & ÇD \\
\hline ÜS & & & & $\mathrm{EE}$ & & & & EE & & & & EE \\
\hline Sís & CONWIP & Kanban & İE & ÜS & CONWIP & Kanban & $\dot{\mathrm{I}} \mathrm{E}$ & ÜS & CONWIP & Kanban & $\dot{\mathrm{I}} \mathrm{E}$ & ÜS \\
\hline CONWIP & $\mathrm{EE}$ & $\mathrm{Y}$ & ÇY & $\mathrm{H}$ & EE & $\mathrm{Y}$ & $\mathrm{Y}$ & $\mathrm{Y}$ & $\mathrm{EE}$ & OY & KY & ÇY \\
\hline Kanban & & $\mathrm{EE}$ & KY & ÇY & & $\mathrm{EE}$ & ÇY & KY & & EE & ÇY & $\mathrm{Y}$ \\
\hline İE & & & $\mathrm{EE}$ & ÇD & & & EE & $\mathrm{D}$ & & & EE & ÇD \\
\hline ÜS & & & & $\mathrm{EE}$ & & & & EE & & & & EE \\
\hline TDU & CONWIP & Kanban & İE & ÜS & CONWIP & Kanban & İE & ÜS & CONWIP & Kanban & İE & ÜS \\
\hline CONWIP & EE & ÇD & KD & $\mathrm{D}$ & EE & ÇD & $\mathrm{KD}$ & $\mathrm{D}$ & EE & D & KD & OD \\
\hline Kanban & & $\mathrm{EE}$ & OD & $\mathrm{EE}$ & & $\mathrm{EE}$ & ÇD & D & & EE & ÇD & $\mathrm{EE}$ \\
\hline İE & & & $\mathrm{EE}$ & $\mathrm{EE}$ & & & $\mathrm{EE}$ & $\mathrm{D}$ & & & $\mathrm{EE}$ & $\mathrm{D}$ \\
\hline ÜS & & & & $\mathrm{EE}$ & & & & $\mathrm{EE}$ & & & & $\mathrm{EE}$ \\
\hline İSDU & CONWIP & Kanban & İE & ÜS & CONWIP & Kanban & İE & ÜS & CONWIP & Kanban & İE & ÜS \\
\hline CONWIP & $\mathrm{EE}$ & KD & KD & $\mathrm{KD}$ & $\mathrm{EE}$ & KD & $\mathrm{KD}$ & KD & $\mathrm{EE}$ & KD & $\mathrm{KD}$ & KD \\
\hline Kanban & & EE & OD & $\mathrm{EE}$ & & $\mathrm{EE}$ & ÇD & OY & & EE & OD & EE \\
\hline İE & & & $\mathrm{EE}$ & $\mathrm{EE}$ & & & $\mathrm{EE}$ & $\mathrm{EE}$ & & & $\mathrm{EE}$ & $\mathrm{Y}$ \\
\hline ÜS & & & & $\mathrm{EE}$ & & & & $\mathrm{EE}$ & & & & $\mathrm{EE}$ \\
\hline PGGD & CONWIP & Kanban & İE & ÜS & CONWIP & Kanban & İE & ÜS & CONWIP & Kanban & İE & ÜS \\
\hline CONWIP & EE & $\mathrm{Y}$ & KY & $\mathrm{H}$ & EE & $\mathrm{Y}$ & ÇY & OY & $\mathrm{EE}$ & ÇY & ÇY & OY \\
\hline Kanban & & $\mathrm{EE}$ & KY & OY & & $\mathrm{EE}$ & ÇY & $\mathrm{EE}$ & & $\mathrm{EE}$ & $\mathrm{Y}$ & $\mathrm{EE}$ \\
\hline İE & & & $\mathrm{EE}$ & $\mathrm{KD}$ & & & $\mathrm{EE}$ & $\mathrm{KD}$ & & & $\mathrm{EE}$ & ÇD \\
\hline ÜS & & & & $\mathrm{EE}$ & & & & EE & & & & EE \\
\hline
\end{tabular}


Tablo 5. Birleştirilmiş karşılaştırma matrisi

\begin{tabular}{lllllll}
\hline Kriterler & KKK & SiS & TDU & İSDU & PGGD \\
\hline KKK & $([0.5,0.5],[0.5,0.5])$ & $([0.17,0.37],[0.66,0.36])$ & $([0.32,0.54],[0.70,0.40])$ & $([0.52,0.76],[0.84,0.60])$ & $([0.41,0.66],[0.74,0.45])$ \\
SíS & $([0.34,0.64],[0.83,0.63])$ & $([0.5,0.5],[0.5,0.5])$ & $([0.46,0.67],[0.86,0.61])$ & $([0.77,1],[10.97])$ & $([0.53,0.75],[0.900 .68])$ \\
TDU & $([0.30,0.60],[0.68,0.46])$ & $([0.14,0.39],[0.54,0.33])$ & $([0.5,0.5],[0.5,0.5])$ & $([0.68,1],[10.86])$ & $([0.56,0.78],[0.93,0.71])$ \\
İSDU & $([0.16,0.40),[0.48,0.24])$ & $([0,0.03],[0.23,0])$ & $([0.57,1],[0.74,0.54])$ & $([0.5,0.5],[0.5,0.5])$ & $([0.14,0.35],[0.62,0.31])$ \\
PGGD & $([0.26,0.55],[0.59,0.34])$ & $([0.10,0.32],[0.47,0.25])$ & $([0.07,0.29],[0.44,0.22])$ & $([0.38,0.69],[0.86,0.65])$ & $([0.5,0.5],[0.5,0.5])$ \\
\hline
\end{tabular}

Tablo 6. Skor değerlendirme matrisi

\begin{tabular}{llllll}
\hline Kriterler & KKK & SíS & TDU & İSDU & PGGD \\
\hline KKK & {$[0,0]$} & {$[-0.19,-0.29]$} & {$[-0.08,-0.16]$} & {$[-0.08,0.08]$} & {$[-0.04,-0.08]$} \\
SíS & {$[-0.29,0.01]$} & {$[0,0]$} & {$[-0.15,-0.19]$} & {$[-0.20,0]$} & {$[-0.15,-0.15]$} \\
TDU & {$[-0.16,-0.08]$} & {$[-0.19,-0.15]$} & {$[0,0]$} & {$[-0.18,0]$} & {$[-0.15,-0.15]$} \\
İSDU & {$[-0.08,-0.08]$} & {$[0,-0.20]$} & {$[0.03,0.26]$} & {$[0,0]$} & {$[-0.17,-0.27]$} \\
PGGD & {$[-0.08,-0.04]$} & {$[-0.15,0.07]$} & {$[-0.15,-0.15]$} & {$[-0.27,0.04]$} & {$[0,0]$} \\
\hline
\end{tabular}

Tablo 7. Aralık çarpım matrisi

\begin{tabular}{llllll}
\hline Kriterler & KKK & SIS & TDU & ÍSDU & PGGD \\
\hline KKK & {$[1,1]$} & {$[0.64,0.51]$} & {$[0.83,0.69]$} & {$[0.83,1.20]$} & {$[0.91,0.83]$} \\
SİS & {$[0.51,1.02]$} & {$[1,1]$} & {$[0.70,0.64]$} & {$[0.63,1]$} & {$[0.70,0.70]$} \\
TDU & {$[0.69,0.83]$} & {$[0.64,0.70]$} & {$[1,1]$} & {$[0.66,1]$} & {$[0.70,0.70]$} \\
ÍSDU & {$[0.83,0.83]$} & {$[1,0.63]$} & {$[1.07,1.81]$} & {$[1,1]$} & {$[0.67,0.53]$} \\
PGGD & {$[0.83,0.91]$} & {$[0.70,1.17]$} & {$[0.70,0.70]$} & {$[0.53,1.09]$} & {$[1,1]$} \\
\hline
\end{tabular}


Tablo 8. Öncelik vektörü

\begin{tabular}{ll}
\hline Kriterler & Öncelik \\
\hline KKK & {$[0.11,0.19]$} \\
SİS & {$[0.08,0.19]$} \\
TDU & {$[0.09,0.19]$} \\
İSDU & {$[0.13,0.21]$} \\
PGGD & {$[0.09,0.22]$} \\
\hline
\end{tabular}

Tablo 9. Olabililik derece matrisi ve kriterlerin ă̆ırlıkları

\begin{tabular}{llllllll}
\hline & KKK & SİS & TDU & İSDU & PGGD & $w_{i}$ & $w_{i}^{T}$ \\
\hline KKK & 0.5 & 0.56 & 0.55 & 0.55 & 0.47 & 0.82 & 0.20 \\
SİS & 0.44 & 0.5 & 0.48 & 0.52 & 0.43 & 0.77 & 0.19 \\
TDU & 0.45 & 0.52 & 0.5 & 0.32 & 0.43 & 0.74 & 0.18 \\
İSDU & 0.45 & 0.48 & 0.68 & 0.5 & 0.58 & 0.83 & 0.20 \\
PGGD & 0.53 & 0.57 & 0.57 & 0.42 & 0.5 & 0.81 & 0.20 \\
\hline
\end{tabular}

Tablo 10. Alternatiflerin siralanmast

\begin{tabular}{lllllll}
\hline \multicolumn{3}{c}{ Kriterler } & & & \multicolumn{2}{c}{ Stralama } \\
\cline { 2 - 6 } Alternatives & 0.20 & 0.19 & 0.18 & 0.20 & 0.20 & \\
\hline CONWIP & 0.41 & 0.24 & 0.29 & 0.31 & 0.31 & $\mathbf{0 . 3 0}$ \\
Kanban & 0.14 & 0.45 & 0.30 & 0.28 & 0.27 & 0.27 \\
İE & 0.20 & 0.26 & 0.24 & 0.24 & 0.20 & 0.22 \\
ÜS & 0.21 & 0.15 & 0.14 & 0.17 & 0.17 & 0.16 \\
\hline
\end{tabular}

Yukarıda da bahsedildiği üzere Tablo 10' da ki değerler en iyi sonucu CONWIP üretim kontrol sisteminin sağladığını göstermektedir. $\mathrm{Bu}$ durumda uzmanların görüşleri ADSBAHP yöntemi ile değerlendirildiğinde CONWIP sisteminin SHÜS için en uygun alternatif olduğu söylenebilir. CONWIP sisteminden sonra ikincil sırayı Kanban sistemi ve üçüncü sırayı itme esaslı üretim kontrol sisteminin aldığı görülmektedir. Ürün salınım sisteminin ise son sırada yer aldığı görülmektedir.

CONWIP sisteminin yerleşim bakımından esnek olan üretim ortamlarında daha iyi sonuçlar verdiği literatürdeki çalışmalardan da bilinmektedir. Aglan ve Durmusoglu [5] yapısal olarak SHÜS benzeri olan melez üretim sistemleri için CONWIP kontrol sistemini önerdiğinde bu duruma vurgu yapmışlardır. CONWIP sayesinde sistem içerisindeki stok seviyesi çekme esaslı kontrol edilerek itme esaslı bir üretim uygulanmaktadır. Bu durum SHÜS içerisindeki sanal hücrelerin yeni ürün kabulüne ve değişimine olanak sağlamaktadır. Kriterler açısından değerlendirildiğinde CONWIP sisteminin kullanım ve kontrol kolaylığı sağlaması bu sisteminin ilk sırada yer almasında önemli bir katkı sunmuştur. Kanban sisteminin ikinci sırada yer alması bu sistemin talep yapısı düzgün ve ürün çeşitliliğinin fazla olmadığı üretim ortamları için daha uygun olduğunu göstermektedir. SHÜS ürün çeşitliliğine ve talep dalgalanmalarına izin verdiği için Kanban alternatifi bu sistem için ikinci sırada yer almaktadır. Kriterler açısından değerlendirildiğinde Kanban sistemi her ne kadar süreç içi stok kriteri için uygun bir alternatif olsa da SHÜS için kullanım ve kontrol kolaylığı sağlamaması ilk sırada yer almaması açısından önemli bir etken olmuştur. İtme esaslı üretim kontrol sistemi süreç içi stokları göz önünde bulundurmamakta ve malzeme ihtiyaç planlaması temelli merkezi kontrol esaslı şekilde yürütülmektedir. Bu durum İE alternatifinin üçüncü sırada yer almasına neden olmuştur. Kriterler göz önünde bulundurulduğunda İE sistemi için her kriter skor değerinin birbirine yakın ve yüksek olmaması bu sistemin SHÜS için çok uygun bir sistem olmadığını göstermektedir. ÜS kontrol sistemi genel anlamda üretim sürecinde işyükünün kontrolü için kullanılmaktadır ve bu durumun uzman değerlendirilmelerinde ön plana çıktığı görülmektedir. Kriterler bazında değerlendirildiğinde ÜS tüm kriterlerden en düşük skor değerlerini almıştır. Bu nedenle ÜS son 
sırada yer almıştır ve SHÜS için üretim kontrol sistemi olarak kullanımının uygun olmadığı sonucuna varılmaktadır. Ancak, bu sistemin SHÜS' de işyükü kontrolü için kullanılabilir olduğu literatürdeki çalışmalar incelendiğinde ortaya çıkmaktadır.

Kriterler alternatiflerden bağımsız olarak değerlendirildiğinde tüm kriterlerin skor değerlerinin birbirine yakın olması kriterler arasında bir öncelik olmadığının ve tüm kriterlerin en uygun alternatifin belirlenmesinde oldukça önemli olduğunu göstermektedir.

\section{SONUÇ (CONCLUSION)}

Son y1llarda müşteri isteklerinin yüksek çeşitlilik göstermesi ve taleplerinde yaşanan dalgalanmalar geleneksel hücresel üretim sistemlerinin kullanılmasını zorlaştırmaktadır. Bu duruma önlem olarak sanal hücresel üretim sistemleri önerilmektedir. $\mathrm{Bu}$ sistem sayesinde hem yüksek çeşitlilikte ürün üretilebilmekte hem de operasyonel anlamda kolaylıklar sağlanabilmektedir. Yeni bir ürün ailesinin sistem tarafından kabulü herhangi bir yerleşim değişikliğine neden olmadığı için oldukça kolay olmaktadır. Hücreler sanal olarak belirlendiği için talepte meydana gelen varyasyonlara sistemin efektif olarak cevap verebilmesi daha kolay olmaktadır. Bu sistemlerde temel olarak ele alınmasi gereken problem ise sistemin üretim kontrolünün nasıl sağlanacağıdır. Literatürde üretim kontrol sistemleri için birçok alternatif bulunmaktadır ancak her alternatif her üretim sistemi için uygun olmamaktadır. $\mathrm{Bu}$ nedenle ele alınan üretim ortamı için uygun üretim kontrol sisteminin belirlenmesi oldukça önemlidir. Bu çalışma içerisinde ele alınan SHÜS için dört farklı üretim kontrol sistem alternatifi beş kriter ve üç uzman görüşü 1şı̆̆ında ADSBAHP metodu kullanılarak değerlendirilmiştir. CONWIP sisteminin karmaşık üretim yerleşimine sahip ortamlarda uygulanabilirliğinin kolay olması bu kontrol sisteminin alternatifler arasında ilk sıraya yerleşmesinde etkin olmuştur. Kriter ağırlıklarının birbirine yakın olması alternatiflerin herhangi bir kriterden yüksek skor elde etmesiyle sıralamalarının değişebileceğinin bir göstergesidir. CONWIP sistemi beş kriterin üç tanesinden en yüksek skor değerlerini elde etmiştir ve böylece SHÜS için üretim kontrol sistemi olarak en uygun alternatif olarak belirlenmiştir. ÜS kontrol sisteminin beş kriterin dört tanesinden en düşük skor elde etmesi bu alternatifin son sırada yer almasına neden olmuştur. Ancak daha önce de belirtildiği üzere ÜS sistemi SHÜS için üretim kontrol sistemi olarak kullanılamasa bile işyükü kontrolü amaçı kullanılabilecektir.

Gelecek çalışmalarda ADSBAHP' dan farklı yöntemler kullanılarak elde edilen sonuçlar karşılaştırılabileceği gibi aralık değerli sezgisel bulanık kümeler farklı çok kriterli karar verme teknikleri ile melez olarak aynı problem uyarlanabilir. SHÜS için alternatiflerin ve kriterlerin belirlenmesinde farklı çalışmalar göz önünde bulundurulabilir. Bir diğer önemli nokta ise problem için uygulanan yöntem farklı üretim ortamları içinde uygulanarak uygun üretim kontrol yöntemleri önerilebilir. 


\section{KAYNAKLAR (REFERENCES)}

[1] Rajesh, K. D., Krishna, M. M., Ali, M. A., \& Chalapathi, P. V. (2017). A Modified Hybrid Similarity Coefficient Based Method for Solving the Cell Formation Problem in Cellular Manufacturing System. Materials Today: Proceedings, 4(2), 1469-1477.

[2] Venkataramanaiah, S. (2008). Scheduling in cellular manufacturing systems: an heuristic approach. International Journal of Production Research, 46(2), 429-449.

[3] Yilmaz, O. F., Cevikcan, E., \& Durmusoglu, M. B. (2016). Scheduling batches in multi hybrid cell manufacturing system considering worker resources: A case study from pipeline industry. Advances in Production Engineering \& Management, 11(3), 192.

[4] Norman, B. A., Tharmmaphornphilas, W., Needy, K. L., Bidanda, B., \& Warner, R. C. (2002). Worker assignment in cellular manufacturing considering technical and human skills. International Journal of Production Research, 40(6), 1479-1492.

[5] Aglan, C., \& Durmusoglu, M. B. (2015). Lot-splitting approach of a hybrid manufacturing system under CONWIP production control: a mathematical model. International Journal of Production Research, 53(5), 1561-1583.

[6] Dakov, I., Lefterova, T., \& Petkova, A. (2010). Layout and Production Planning of Virtual Cellular Manufacturing Systems for Mechanical Machining. The Journal of Economic Asymmetries, 7(1), 4367.

[7] Kesen, S. E. (2010). Sanal İmalat Hücrelerinde İ̧̧ Çizelgelenmesi İçin Yeni Çözüm Yaklaşımları, Doktora Tezi, Gazi Üniversitesi Fen Bilimleri Enstitüsü, Ankara.

[8] Mahdavi, I., Aalaei, A., Paydar, M. M., \& Solimanpur, M. (2009, July). Production planning and cell formation in dynamic virtual cellular manufacturing systems with worker flexibility. In Computers \& Industrial Engineering, 2009. CIE 2009. International Conference on (pp. 663-667). IEEE.

[9] Nomden, G., \& van der Zee, D. J. (2008). Virtual cellular manufacturing: Configuring routing flexibility. International Journal of Production Economics, 112(1), 439-451.

[10] Grosfeld-Nir, A., Magazine, M., \& Vanberkel, A. (2000). Push and pull strategies for controlling multistage production systems. International Journal of Production Research, 38(11), 2361-2375.

[11] Mertins, K., \& Lewandrowski, U. (1999). Inventory safety stocks of Kanban control systems. Production Planning \& Control, 10(6), 520-529.

[12] Spearman, M. L., Woodruff, D. L., \& Hopp, W. J. (1990). CONWIP: a pull alternative to kanban. The International Journal of Production Research, 28(5), 879-894.

[13] Cevikcan, E., \& Durmusoglu, M. B. (2014). An integrated job release and scheduling approach on parallel machines: An application in electric wire-harness industry. Computers \& Industrial Engineering, 76, 318-332.

[14] Spearman, M. L., \& Zazanis, M. A. (1992). Push and pull production systems: issues and comparisons. Operations research, 40(3), 521-532.

[15] Steele, D. C., \& Malhotra, M. K. (1997). Factors affecting performance of period batch control systems incellular manufacturing. International journal of production research, 35(2), 421-446.

[16] Li, J. W., \& Barnes, D. J. (2000). Investigating the factors influencing the shop performance in a job shop environment with kanban-based production control. International Journal of Production Research, 38(18), 4683-4699. 
[17] Ryan, S. M., \& Fred Choobineh, F. (2003). Total WIP and WIP mix for a CONWIP controlled job shop. IIE Transactions, 35(5), 405-418.

[18] Islam, N., \& Mohamed, P. S. (2003). Coexistence of JIT and MRP in a manufacturing cell. International Journal of Modelling and Simulation, 23(4), 251-257.

[19] Sharma, S., \& Agrawal, N. (2009). Selection of a pull production control policy under different demand situations for a manufacturing system by AHP-algorithm. Computers \& Operations Research, 36(5), 1622-1632.

[20] Li, J. W. (2010). Simulation study of coordinating layout change and quality improvement for adapting job shop manufacturing to CONWIP control. International Journal of Production Research, 48(3), 879-900.

[21] Moreira, M. D. R. A., \& Alves, R. A. F. (2012). Input-output control order release mechanism in a job-shop: how workload control improves manufacturing operations. International Journal of Computational Science and Engineering, 7(3), 214-223.

[22] Gong, Q., Yang, Y., \& Wang, S. (2014). Information and decision-making delays in MRP, KANBAN, and CONWIP. International Journal of Production Economics, 156, 208-213.

[23] Müller, E., Tolujew, J., \& Kienzle, F. (2014). Push-Kanban-a kanban-based production control concept for job shops. Production Planning \& Control, 25(5), 401-413.

[24] Romagnoli, G. (2015). Design and simulation of CONWIP in the complex flexible job shop of a Make-To-Order manufacturing firm. International Journal of Industrial Engineering Computations, 6(1), 117-134.

[25] Thürer, M., Land, M. J., Stevenson, M., \& Fredendall, L. D. (2016). Card-based delivery date promising in high-variety manufacturing with order release control. International Journal of Production Economics, 172, 19-30.

[26] Konefal, J. G. (2017). Applying factory physics to manual assembly at an aerospace fabrication site (Doctoral dissertation, Massachusetts Institute of Technology).

[27] Atanassov, K. T. (1989). More on intuitionistic fuzzy sets. Fuzzy sets and systems, 33(1), 37-45.

[28] Xu, Z. S., \& Jian, C. H. E. N. (2007). Approach to group decision making based on interval-valued intuitionistic judgment matrices. Systems Engineering-Theory \& Practice, 27(4), 126-133.

[29] Xu, Z. (2010). A method based on distance measure for interval-valued intuitionistic fuzzy group decision making. Information sciences, 180(1), 181-190.

[30] Chen, T. Y., Wang, H. P., \& Lu, Y. Y. (2011). A multicriteria group decision-making approach based on interval-valued intuitionistic fuzzy sets: A comparative perspective. Expert Systems with Applications, 38(6), 7647-7658.

[31] Chen, Z., \& Yang, W. (2012). A new multiple criteria decision making method based on intuitionistic fuzzy information. Expert Systems with Applications, 39(4), 4328-4334.

[32] ZHANG, Y. J., Pei-Jun, M. A., Xiao-Hong, S. U., \& ZHANG, C. P. (2012). Multi-attribute group decision making under interval-valued intuitionistic fuzzy environment. Acta Automatica Sinica, 38(2), 220-227.

[33] Jin, F., Pei, L., Chen, H., \& Zhou, L. (2014). Interval-valued intuitionistic fuzzy continuous weighted entropy and its application to multi-criteria fuzzy group decision making. Knowledge-Based Systems, 59, 132-141. 
[34] Tong, X., \& Yu, L. (2015). A novel MADM approach based on fuzzy cross entropy with intervalvalued intuitionistic fuzzy sets. Mathematical Problems in Engineering, 2015.

[35] Onar, S. C., Oztaysi, B., Otay, İ., \& Kahraman, C. (2015). Multi-expert wind energy technology selection using interval-valued intuitionistic fuzzy sets.Energy, 90, 274-285.

[36] Kahraman, C., Cevik Onar, S., \& Oztaysi, B. (2016). A comparison of wind energy investment alternatives using interval-valued intuitionistic fuzzy benefit/cost analysis. Sustainability, 8(2), 118.

[37] Kahraman, C., Keshavarz Ghorabaee, M., Zavadskas, E. K., Cevik Onar, S., Yazdani, M., \& Oztaysi, B. (2017). Intuitionistic fuzzy EDAS method: an application to solid waste disposal site selection. Journal of Environmental Engineering and Landscape Management, 25(1), 1-12.

[38] Yılmaz, Ö. F., \& Durmuşoğlu, M. B. (2018). An Integrated Methodology for Order Release and Scheduling in Hybrid Manufacturing Systems: Considering Worker Assignment and Utility Workers. In Handbook of Research on Applied Optimization Methodologies in Manufacturing Systems (pp. 125-161). IGI Global. 